\title{
Primary syphilis of the fingers
}

\author{
Z STARZYCKI \\ From the Dermatological Clinic, Medical Academy, Cracow, Poland
}

SUMMARY Six patients were seen with primary syphilitic chancres on their fingers between 1965 and 1980. Of these, two had bipolar chancres on their fingers and genitals resulting from sexual foreplay. Because syphilis is rarely suspected in such cases diagnostic errors are common.

\section{Introduction}

Primary syphilis of the fingers is seldom seen now and usually results from contact with genital lesions during sexual foreplay. In the past, however, these lesions were often found in physicians and nurses as a result of direct contact with infectious ulcers in their patients. ${ }^{1-4}$ The variable clinical appearance of chancres on the fingers frequently results in incorrect or delayed diagnosis. ${ }^{125}$ Recently, Kingsbury et at reported a case of ulcerative syphilitic paronychia and de Koning et $a l^{\prime}$ a patient with primary lesions on two fingers of the right hand.

We report six cases of chancres on the fingers.

\section{Case reports}

Between 1965 and 1980, 2135 cases of early syphilis, including 37 men and five women with 43 extragenital chancres were treated in our clinic. Fifteen $(34 \%)$ patients had primary lesions on the lips, three $(6 \%)$ on the tonsils, two $(5 \%)$ on the tongue, one $(2 \%)$ on the chin, six $(13 \%)$ on the fingers, and 16 $(37 \%)$ in the anorectum. Of these 43 patients, 17 $(40 \%)$ had primary and $26(60 \%)$ secondary syphilis. ${ }^{8}$ All six patients with chancres on the fingers were aged between 30 and 50 years (mean 36 years). Three men were divorced, two married, and one single. In each case syphilis was acquired from casual heterosexual contact with unidentified women or with prostitutes. Five patients gave a history of sexual foreplay. Clinical data and the results of the serological tests for syphilis and of the cerebrospinal fluid are shown in the table.

\section{CASE 1}

A 40 year old divorced man attended the clinic on 12 March 1972. He had had sexual contact with frequent

Address for reprints: Dr Z Starzycki, Dermatological Clinic, Medical Academy, 31-501, ul Kopernika 19a, Cracow, Poland

Accepted for publication 23 November 1982 unknown women, the last contact having been in late December 1971 with a prostitute who was subsequently treated for secondary syphilis. During foreplay he had touched her genitals with his fingers; his left middle finger had been scalded previously. About three weeks later he noted a lesion on this finger. Three weeks before attending the clinic he had been treated with oxytetracycline orally and with ointment for four days.

On examination the nail fold of his left middle finger was oedematous, indurated, and erythematous with two irregular painful ulcers measuring $0.4 \times$ $0.2 \mathrm{~cm}$ and $0.2 \times 0.15 \mathrm{~cm}$ (fig 1). There were no skin or mucosal lesions. The epitrochlear and axillary lymph nodes on the left side were enlarged. Dark field microscopy of the serum expressed from the larger ulcer showed Treponema pallidum. After the first injection of 600000 units of procaine penicillin no Jarisch-Herxheimer reaction occurred.

\section{CASE 2}

A 33 year old divorced man attended the clinic on 10 December 1970. He had been treated for the first time in May 1968 for primary seropositive syphilis with procaine and benzathine penicillin to a total dose of 16.9 megaunits. After treatment serological tests for syphilis became negative.

His most recent sexual contact had been with an unknown woman in the middle of August 1970; he had touched her genitals with his left middle finger which had been injured previously. Two weeks later he noted an ulcer on the erythematous oedematous finger, and was treated in late September 1970 by his general practitioner with three injections of procaine penicillin. In November he noted an ulcer on the inner surface of the prepuce and attended the clinic.

On examination there was an oval indurated ulcer on the inner surface of the prepuce near the fraenum. The distal two thirds of his left middle finger and the nail fold were distinctly oedematous, indurated, dull red, tender, and covered with whitish scales (fig 2). There was bilateral enlargement of the inguinal and 


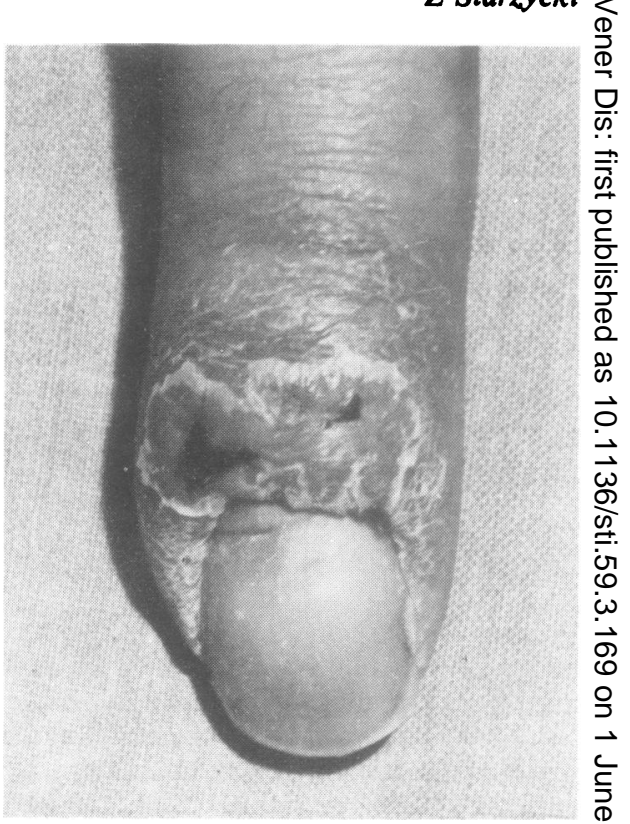

FIG 1 Ulcerous syphilitic paronychia of the left middle finger in a patient (case 1) with primary seropositive syphilis.

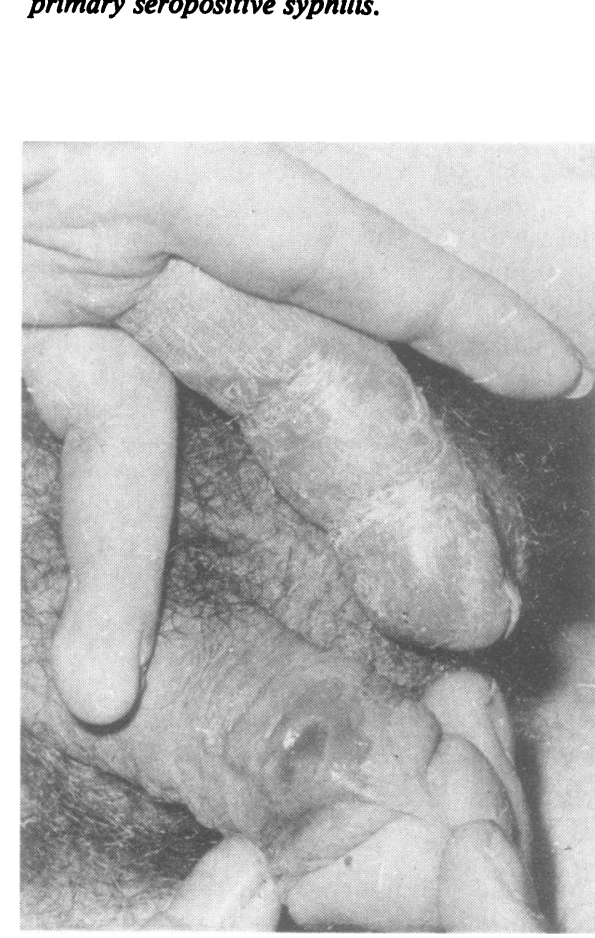

FIG 2 Bipolar chancres on the inner surface of the prepuce and syphilitic dactylitis of the left middle finger in a patient (case 2) with primary seropositive syphilis (reinfection). 
one left epitrochlear lymph nodes. Though there were no mucocutaneous lesions of syphilis he had an infestation with Sarcoptes scabeii and Pthirus pubis. Radiological examination of the chest and fingers showed no abnormalities. Dark field microscopy of serum expressed from the preputial ulcer and eroded surface of the left finger showed typical $T$ pallidum. After the first injection of 600000 units of procaine penicillin there was no increase in temperature.

\section{Discussion}

Extragenital chancres occurred in $2 \%$ of our patients with early syphilis. The incidence of extragenital primary syphilis in reports reviewed by Santler ${ }^{4}$ ranged from $2 \%$ to $10 \%$, and among these data the percentage of chancres on the fingers ranged from $5 \%$ to $10 \% .^{24}$ In our clinic the incidence of primary syphilis of the fingers was $14 \%$ of extragenital chancres. They were found in patients who attended during 1969 to 1972 -that is, when syphilis was epidemic in our country and for a short time afterwards.

The clinical picture in three patients was consistent with ulcerous periungual syphilitic paronychia, and in the remaining three with syphilitic panaritium, including one patient with syphilitic dactylitis, the condition had a chronic course. In all six patients the syphilitic infection of the fingers was acquired during sexual foreplay; the preceding injuries and scalding of fingers may have predisposed to infection.

Bipolar chancres are a rare manifestation of primary syphilis. Lesnikow and Kudriaszow ${ }^{9}$ found only 32 cases of bipolar chancres in published reports and recorded one more seen personally. According to these workers only four cases of bipolar chancre on the fingers and genitals have been reported. We report two more cases. One of our six patients (case 6) developed syphilitic panaritium and four superficial ulcers on the prepuce simultaneously. In the patient in case 2 with bipolar chancres after inadequate treatment the syphilitic ulcerous paronychia progressed to dactylitis.

Recently, Miliawskij ${ }^{10}$ reported a case of early secondary syphilis in a homosexual man with bipolar chancres in the oral cavity and in the anal region. In our study the diagnosis was mistaken in four patients, three of whom (cases 1, 2, and 4) were treated by their general practitioners with antibiotics at low doses and one by surgical incision. In three patients a correct diagnosis was made after the symptoms of early secondary syphilis had developed and in one (case 5) early asymptomatic neurosyphilis was found.

\section{References}

1. Stokes JH, Beerman $\mathbf{H}$, Ingraham NR. Modern clinical syphilology. Philadelphia and London: Saunders WB, 1946: 495-508.

2. Tucker HA, Mulherin JL. Extragenital chancres. A survey of 219 cases. Am J Syph Gonorr Vener Dis 1948; 32:345-64.

3. Ormsby OS, Montgomery H. Diseases of the skin. 8th ed. London: Kimpton H, 1954: 1439-42.

4. Santler R. Genitale and extragenitale Primăraffekte. In: Wiedmann A, ed. Hdb Haut und Geschlkrkh. J. Jadassohn. Erganzungswerk. Berlin, Gottingen, Heidelberg: Springer 1962:626-62.

5. Labouche F, Hénaff R, Cadero B. Syphilis primo-secondaire; chancre digital à localisation inhabituelle. Bull Soc $F r$ Dermatol Syphilol 1967; 74:154-5.

6. Kingsbury DH, Chester EC jun, Jansen GT. Syphilitic paronychia: an unusual complaint. Arch Dermatol 1972; 105: 458.

7. de Koning GAJ, Blog FB, Stolz E. A patient with primary syphilis of the hand. $B r J$ Vener Dis 1977;53:386-8.

8. Starzycki Z, Mayer J. Zmiany pierwotne o pozapłciowym umiejscowieniu. Przegl Dermatol 1981;68:475-81.

9. Lesnikow EP, Kudriaszow GK. Bipolarnyje szankry. Wiest Dermatol Wener 1972; 46:82-4.

10. Miliawskij AI. Shuczaj bipolarnogo szankra. Wiest Dermatol Wener 1982;56:71. 